TITLE: EXPERIMENTAL OBSERVATIONS OF THERMAL SPIKES IN MICROWAVE PROCESSING OF CERAMIC OXIDE FIBERS

AUTHOR(S): Gerald J. Vogt

Wesley P. Unruh

James R. Thomas, Jr.

SUBMITTED TO: Gail A. Oare

Director of Publications

Materials Research Society

9800 McKnight Road

Pittsburgh, PA 15237-6006

1994 Spring MRS Meeting

Symposium O: Microwave Processing of Materials IV

San Francisco, CA

April 4-8, 1994 


\title{
EXPERIMENTAL OBSERVATIONS OF THERMAL SPIKES IN MICROWAVE PROCESSING OF CERAMIC OXIDE FIBERS
}

Gerald J. Vogt, Wesley P. Unruh, and J.R. Thomas, Jr*.

Los Alamos National Laboratory, Los Alamos, New Mexico 87545

*On leave from Virginia Polytechnic Institute and State University, Blacksburg, VA 24061

\begin{abstract}
Microwave heating of alumina/silica fiber tows in a single-mode microwave cavity at 2.45 $\mathrm{GHz}$ have produced a surprising thermal spike behavior on the fiber bundles. During a thermal spike, a "hot spot" on the tow brightens rapidly, persists for a few seconds, and rapidly extinguishs. A hot spot can encompass the entire tow in the cavity or just a localized portion of the tow. Some local hot spots propagate along the fiber. Thermal spikes are triggered by relatively small $(<15 \%)$ increases in power, thus having obvious implications for the development of practical microwave fiber processing systems. A tow can be heated through several successive thermal spikes, after which the tow is left substantially cooler than it was originally, although the applied microwave electric field is much larger. X-ray diffraction studies show that after each temperature spike there is a partial phase transformation of the tow material into mullite. . After several excursions the tow has been largely transformed to the new, less lossy phase and is more difficult to heat. Heating experiments with Nextel 550 tows are examined for a pausible explanation of this microwave heating behavior.
\end{abstract}

\section{INTRODUCTION}

Microwave heating in single-mode cavities has potential commercial application in the processing of ceramic oxide filament tows (filament bundles). Process heating of the long filament tows can take advantage of aligning the electric field within the cavity parallel to the long axis of the moving tow. Controlling the tow temperature to avoid excessive heating is a major challenge for successful processing to a strong, flexible tow. In our work on controllable microwave sintering [1-2], aluminosilicate filaments have demonstrated a surprising behavior of thermal spiking with small $(<15 \%)$ increases in microwave power. A hot spot along a stationary tow will brighten rapidly, persist for a few seconds, and rapidly extinguish. A hot spot can encompass the entire tow in the cavity or just a localized portion of the tow. The tow often cools rapidly to a temperature which is lower than it was before the excursion. Frequently, the local hot spot will migrate in either direction along the tow. This paper describes the thermal spiking behavior as found in $3 \mathrm{M}$ Nextel 550 aluminosilicate tows, although the behavior was observed in several commercial aluminosilicate filaments. The impact of this heating behavior on filament process control is examined.

\section{EXPERIMENTAL PROCEDURES}

The microwave heating experiments were conducted in a $\mathrm{TE}_{103}$ single-mode cavity powered with a $3 \mathrm{~kW}$ magnetron source (Gerling Laboratories, Model GL119). The microwave circuit and controls are described in an earlier work [2]. The resonant $\mathrm{TE}_{103}$ caviicy consisted of a water-jacketed stainless-steel section of rectangular waveguide with a coupling iris at the inlet and an adjustable short to tune the cavity frequency. A variable stub tuner was positioned before the iris to minimize the reflected power from the cavity. The loaded Q-factor for the cavity was typically near 1200 . 


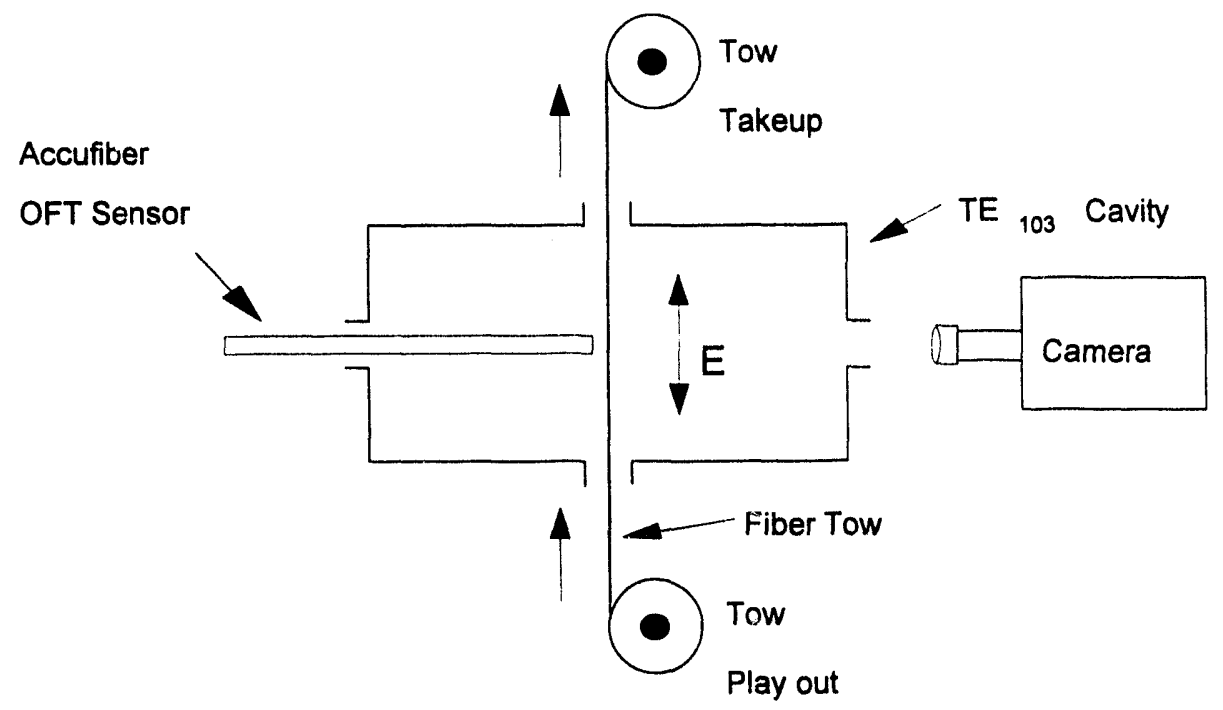

Figure 1. Schematic view of $\mathrm{TE}_{103}$ crvity, showing tow position with OFT temperature sensor and video camera.

The cavity was fabricated with two pairs of opposing circular opening, as depicted in Figure 1, positioned at the first electric field maximum in from the coupling iris. The oxide filament tows were loaded through the paired openings aligned with the transverse electric field in the cavity. The second pair of openings, perpendicular to the transverse electric field, provided for insertion of an optical fiber thermometer and for video recording of the heated tow.

The microwave heating experiments were conducted in air with stationary tow samples loaded parallel to the transverse electric field. Power to cavity and sample was increased by abrupt jumps of 50-90 watts after irregular intervals of 1-to-3 minutes. The sample was allowed to relax to steady-state temperature before increasing the power. The mean tow temperature and heating images were recorded throughout the experiments.

The tow temperature was measured with an optical fiber thermometry (OFT) system (Luxtron Accufiber Model 100C). The lightpipe sensor was inserted into the cavity through an opening perpendicular to the transverse electric field, as shown in Figure 1. Temperature was estimated from the ratio of emitted light detected at $800 \mathrm{~nm}$ and $950 \mathrm{~nm}$, assuming equal emissivities at these wavelengths. The OFT sensor viewed approximately 4-to-5 millimeters of the 34-mm long tow in the cavity.

The temperature measurements are believed to be accurate within $\pm 50^{\circ} \mathrm{C}$, or better. However, the actual accuracy for this type of measurement is presently not known. The OFT measurement was taken for a non-blackbody emitter within a water-cooled dimly-lit cavity. Because the OFT sensor did view a 4-to-6 mm length of the tow, the reported temperatures are probably weighted average values over the observed tow length. The reported temperatures measured by a two-color technique should be relatively insensitive to distance to and position of the emitter and reliable for a material of unknown emissivity.

Heating experiments were video recorded with a color CCD camera and VCR to document transient features of the tow heating behavior. The camera viewed the center third of the heated tow through the opening opposite the OFT sensor (see Figure 1).

Nextel 550 tows were examined for the spike heating behavior in aluminosilicate filaments. The test tows consisted of approximately 200 white filaments with a nominal composition of 73 $\mathrm{w} \%$ alumina and $27 \mathrm{w} \%$ silica, coated with a proprietary organic sizing. The average filarnent diameter was 10-15 microns. The aluminosilicate filaments were largely amorphous in structure with a detectable $\gamma$-alumina phase, but undergo crystallization to mullite near $1250^{\circ} \mathrm{C}$. The tow samples were dip-coated with carbon to provide hybrid preheating for the tows from room 


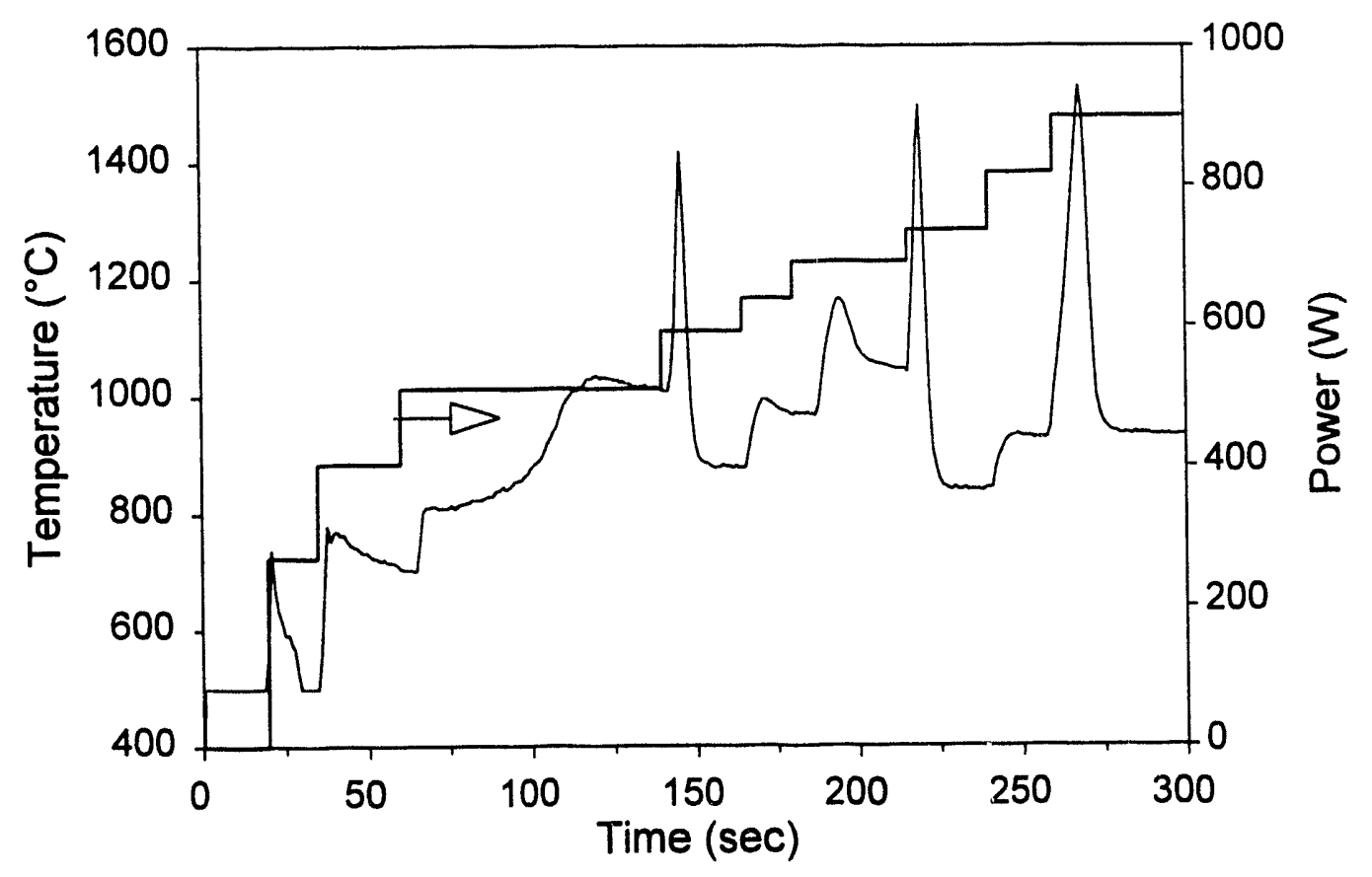

Figure 2. Temperature and power curves for a microwave heating experiment with a stationary Nextel 550 tow.

temperature to $>600^{\circ} \mathrm{C} \mathrm{[1]}$. Above $600^{\circ} \mathrm{C}$ the test filaments sufficiently absorbed the $2.45 \mathrm{GHz}$ microwaves for direct heating to higher temperatures.

The crystallized mullite content of the heated filaments was determined by $x$-ray diffraction with an internal $\alpha$-alumina standard. X-ray diffraction analysis was performed with a Scintag PAD V diffractometer using copper $\mathrm{K}_{\alpha}$ radiation. The $\mathrm{x}$-ray intensities were calibrated against tow samples heated in air at $1400^{\circ} \mathrm{C}$ for 35 minutes.

\section{RESULTS AND DISCUSSION}

\section{Thermal Spikes}

Figure 2 shows typical temperature-vs-time and power-vs-time curves for a heating experiment with Nextel 550 tows. The OFT operational range is between $500^{\circ} \mathrm{C}$ and $2000^{\circ} \mathrm{C}$, giving a flat response at $500^{\circ} \mathrm{C}$. The interesting features are the thermal (or heating) spikes, which took place at 140,215 , and 260 seconds. With the sudden, but small, increase in total power, the mean tow temperature rapidly rises to over $1400^{\circ} \mathrm{C}$ in several seconds, as if going into thermal runaway. However, the tow temperature then rapidly falls back to a value between $800^{\circ}$ and $1000^{\circ} \mathrm{C}$. The same behavior was observed for tows that were pulled through the cavity at a constant power level. As fresh tow entered the cavity, it was successively heated to a red glow by the carbon coating and then to white hot at measured temperatures near $1200^{\circ} \mathrm{C}$. However, the moving tow appeared to stop heating before leaving the cavity, as the visible radiation had extinguished.

In Figure 2, the temperature changes during the initial 140 seconds correspond to the oxidation of the carbon coating. At the first temperature rise (at 20 seconds), a significant fraction of the carbon coating was rapidly burnt away. The remaining carbon was then slowly oxidized away and completely removed after the temperature spike at 140 seconds. The rise in 
temperature from $800^{\circ} \mathrm{C}$ to $1000^{\circ} \mathrm{C}$ between 100 to 135 seconds was the transition from the red glow of heated carbon to the white hot of heated aluminosilicate under constant microwave power.

The thermal spike at 140 seconds was triggered by a power increase from $511 \mathrm{~W}$ to $593 \mathrm{~W}$, a $16 \%$ increase in power. Surprisingly, the final temperature after the heating spike was $\sim 100^{\circ} \mathrm{C}$ lower than the starting temperature. A similar event occurred for the thermal spike at 215 seconds with a temperature difference of $\sim 200^{\circ} \mathrm{C}$. In that case, the power was increased by $\sim 80 \mathrm{~W}$, a $11 \%$ change. However, the starting and final temperatures were nearly equal for the heating spike at 260 seconds. Also, the power increases at 165,180 , and 240 seconds produced only step increases in the tow temperature. Repeated experiments over a power range of $400 \mathrm{~W}$ to $1200 \mathrm{~W}$ reproduced the type of heating behavior shown in Figure 2.

Heating the tow with greater levels of microwave power altered the filament tow so that greater power levels were required to maintain the tow temperature at $900^{\circ}-1000^{\circ} \mathrm{C}$. For example, after increasing the microwave power in gradual steps to $900 \mathrm{~W}$, a decrease in power by $50 \mathrm{~W}$, or more, produced a rapid drop in temperature to $<500^{\circ} \mathrm{C}$, extinguishing the hot tow.

A reasonable explanation for the microwave heating behavior of the aluminosilicate filaments is a systematic decrease in the tow dielectric loss factor with each heating spike above $1200^{\circ} \mathrm{C}$. The heat $\mathrm{Q}$ generated per unit volume in the filaments is given by:

$$
Q=2 \pi f \varepsilon_{o} \varepsilon_{r}^{\prime \prime} E^{2}
$$

where $\mathrm{f}$ is the frequency, $\varepsilon_{0}$ is the permittivity of free space, $\varepsilon_{\mathrm{r}}{ }^{\prime \prime}$ is the dielectric loss factor, and $\mathrm{E}$ is the local electric field in the filament. Local heating is therefore directly proportional to the loss factor. Also, in the $\mathrm{TE}_{103}$ cavity heating is proportional to $\mathrm{E}^{2}$ and to the total microwave power. With an increase in power and electric field, the tow should rapidly heat to higher temperatures above $1200^{\circ} \mathrm{C}$ within several seconds. Then, to cool just as rapidly would require a significant drop in the heating rate. Radiative cooling at a $T^{*}$ rate would not be able to produce this effect alone. However, if the dielectric loss factor should suddenly decrease, the heating rate would drop sufficiently to allow rapid cooling by radiation loss under a stronger electric field. In the heating experiments, the input power during the thermal spikes remained constant $(<1 \mathrm{~W})$ without a change in the reflected power from the cavity. We, therefore, believe that the dielectric loss factor for the tow decreases sufficiently during the thermal spike to allow radiative cooling back to $900^{\circ}-1000^{\circ} \mathrm{C}$ before thermal runaway can occur. A drop in $\varepsilon_{\mathrm{r}}$ " would also be consistent with the observed changes in temperature with increasing power. For example, a lower $\varepsilon_{\mathrm{r}}$ " value after the heating spike could give a final tow temperature lower than the starting temperature despite a larger electric field in the cavity.

Microwave heating above $1200^{\circ} \mathrm{C}$ produced a new mullite phase within the aluminosilicate fibers. The original filaments consisted of amorphous alumina-silica and $\gamma$-alumina phases. Each thermal spike, like those in Figure 2, generated only a partial crystallization of the aluminosilicate filaments. Initial hybrid heating with the carbon coatings did not alter the crystalline structure of the filaments, as detectable by x-ray diffraction. Heating the aluminosilicate filament with increasingly larger amounts of microwave power did yield a larger fraction of mullite in the final tow, as shown in Figure 3. Successive heating up to $1200 \mathrm{~W}$ converted $\sim 65 \mathrm{w} \%$ of the filaments in the cavity to mullite. The initial thermal spike produced between 10-to-15w\% mullite. The conversion values in Figure 3 between 20 and 25w\% represent two successive heating spikes for a tow sample.

Conversion of the filaments to mullite is a feasible mechanism for the continual drop in the dielectric loss factor for the filament tow. The new mullite phase would have to possess a lower dielectric loss, sufficiently smaller to reduce local heating in the mullite domains. This hypothesis is reasonable since, after several thermal spikes, the tow has been largely transformed to the new mullite phase and is more difficult to heat. High-temperature dielectric measurements for carbon-coated Nextel 550 are needed to verify this assumption. Numerical modeling of the heat transfer during the microwave heating of thin cylinders does support this hypothesis [3]. The model assumes that thermal spikes result primarily from the exponential 


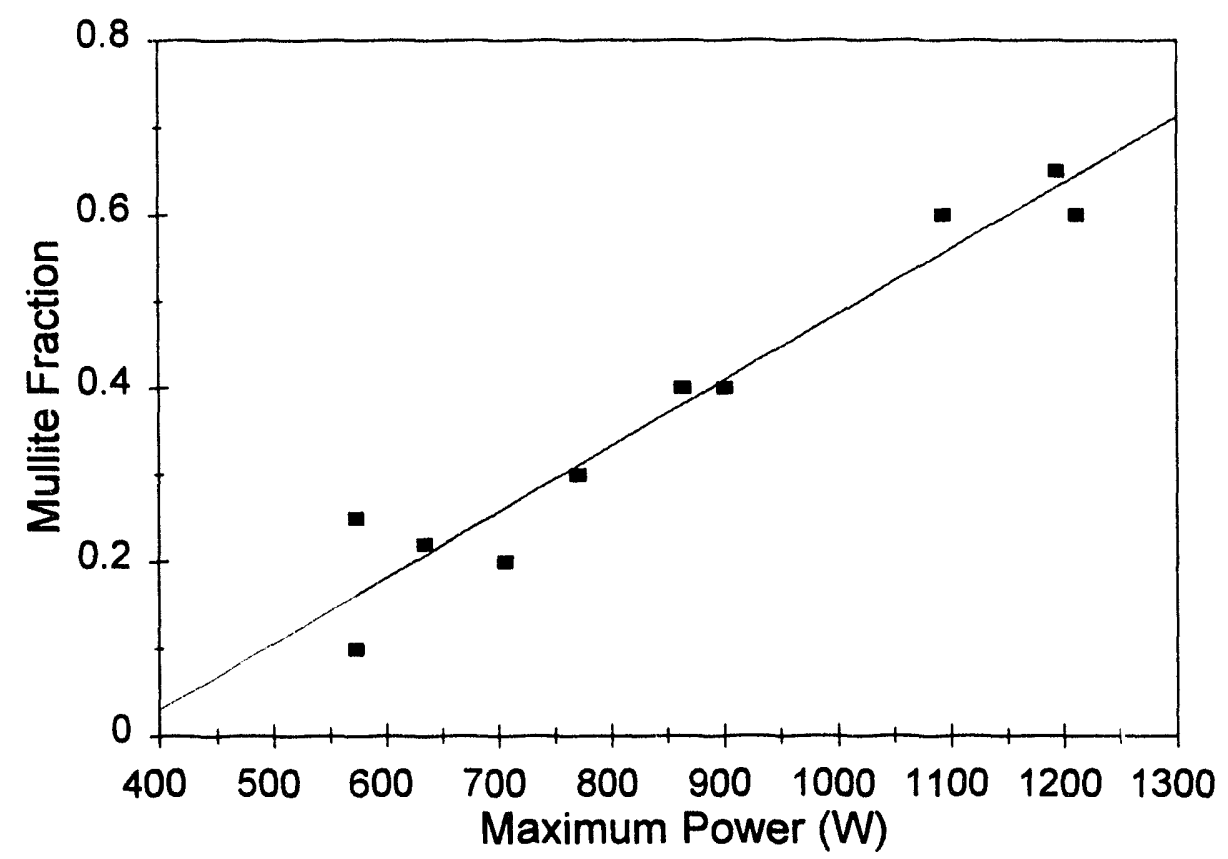

Figure 3. Yield of new mullite phase with microwave power used to process a stationary Nextel 550 tow.

temperature dependence of the dielectric loss $\varepsilon_{\mathrm{r}}{ }^{\prime \prime}$ and mullite formation in the tow. The volume fraction of material transformed depends upon the product of temperature and time during the thermal spike. The model does qualitatively reproduce the observed thermal responses to increasing microwave power.

The thermal spike behavior could have significant impact on the microwave sintering of aluminosilicate filaments. This behavior offers a mechanism for self-regulated heating by microwaves that cannot be duplicated by conventional electrical heating. Microwave sintering would be controlled by an internal shutoff mechanism within the very filaments being processed. Heating at a power level near that required to trigger the first thermal spike may sinter the filaments with a minimum of crystallization.

\section{Hot Spot Migration}

One more significant observation is the apparent migration of some hot spots along the tow in the cavity. A hot spot is a tow section that is experiencing a thermal spike due to a sudden power increase. Most hot spots simply go out without moving. Occasionally, hot spots can propagate along the tow in either direction. The hot spot forms in view of the camera and then migrates out of view after several seconds. Hot-spot mobility is commonly found in tows that have been processed with a minimum of two thermal spikes.

A possible mechanism for the hot-spot migration is the non-uniform dielectric loss along the tow produced by non-uniform heating and mullite formation. A sudden power rise generates a local hot spot at an area of higher dielectric loss. The initial hot spot may begin to heat an adjacent tow section by conduction and radiation, triggering this new area to absorb microwaves in a thermal spike. The hot spot could then migrate along the tow with the rapid ccoling of the initiating spot area behind the new hot spot as it forms. The result is the apparent movement of the hot spot in a wave of new hot spots forming and old ones expiring. 
Experiments have surprisingly produced hot spots moving in one direction only. Although we can theoretically expect the hot spots moving in both directions simultaneously, this behavior was not observed in our experiments. Our numerical model [3] did predict hot spot migration from a perturbation in the dielectric loss factor on the tow, although a perturbation at the center of the tow in the cavity always generated a pair of hot spots moving in opposite directions. We do not have an explanation for the lack of hot-spot pair formation in the experiments.

\section{CONCLUSIONS}

Microwave heating experiments with stationary filament tows in a $\mathrm{TE}_{103}$ cavity have found a thermal spike behavior in Nextel 550 and other commercial aluminosilicate tows. Small increases $(<15 \%)$ in the input power can trigger a rapid rise in the tow temperature, followed by an equally rapid fall in the tow temperature. Thermal spikes to temperatures above $1200^{\circ} \mathrm{C}$ induce a partial crystallization of the Nextel 550 to mullite. Continued processing with thermal spikes made the tow more difficult to heat, requiring greater power levels to maintain heating. The observations suggest that the new mullite phase has a smaller dielectric loss factor than the starting material. A resulting reduction in the dielectric loss is a possible mechanism for the rapid cooling that occurs after the initial rapid heating. This behavior offers a mechanism for self-regulated heating by microwaves that cannot be duplicated by conventional electrical heating.

During microwave heating, the hot spots have demonstrated a surprisingly mobility. The hot spots can occasionally propagate in either direction along the tow.

\section{ACKNOWLEDGMENTS}

This work was supported by the Department of Energy, Office of Industrial Technologies, Advanced Industrial Materials Program. We give thanks to Allan Holtz of the $3 \mathrm{M}$ Company for preparing and supplying the Nextel ${ }^{\mathrm{TM}} 550$ filaments.

\section{REFERENCES}

1. G.J. Vogt and W.P. Unruh, "Processing Aerosols and Filaments in a $\mathrm{TM}_{010}$ Microwave Cavity at $2.45 \mathrm{GHz}$ " in Microwave Processing of Materials III, edited by R.L. Beatty, W.H. Sutton, and M.F. Iskander (Mater. Res. Soc. Proc. 269, Pittsburgh, PA, 1992) pp. 245-250.

2. G.J. Vogt and W.P. Unruh, "Microwave Hybrid Heating of Alumina Filaments" in Microwaves: Theory and Application in Materials Processing II, edited by D.E. Clark, W.R. Tinga, and J.R. Laia, Jr. (Ceramic Transactions 36, The American Ceramic Society, Westerville, OH, 1993) pp. 297-306.

3. J.R. Thomas, Jr., W.P. Unruh, and G.J. Vogt, "Mathematical Model of Thermal Spikes in Microwave Heating of Ceramic Oxide Fibers," published in this proceedings.

\section{DISCLAIMER}

\footnotetext{
This report was prepared as an account of work sponsored by an agency of the United States Government. Neither the United States Government nor any agency thereof, nor any of their employees, makes any warranty, express or implied, or assumes any legal liability or responsibility for the accuracy, completeness, or usefulness of any information, apparatus, product, or process disclosed, or represents that its use would not infringe privately owned rights. Reference herein to any specific commercial product, process, or service by trade name, trademark, manufacturer, or otherwise does not necessarily constitute or imply its endorsement, recommendation, or favoring by the United States Government or any agency thereof. The views and opinions of authors expressed herein do not necessarily state or reflect those of the United States Government or any agency thereof.
} 
$1 !$
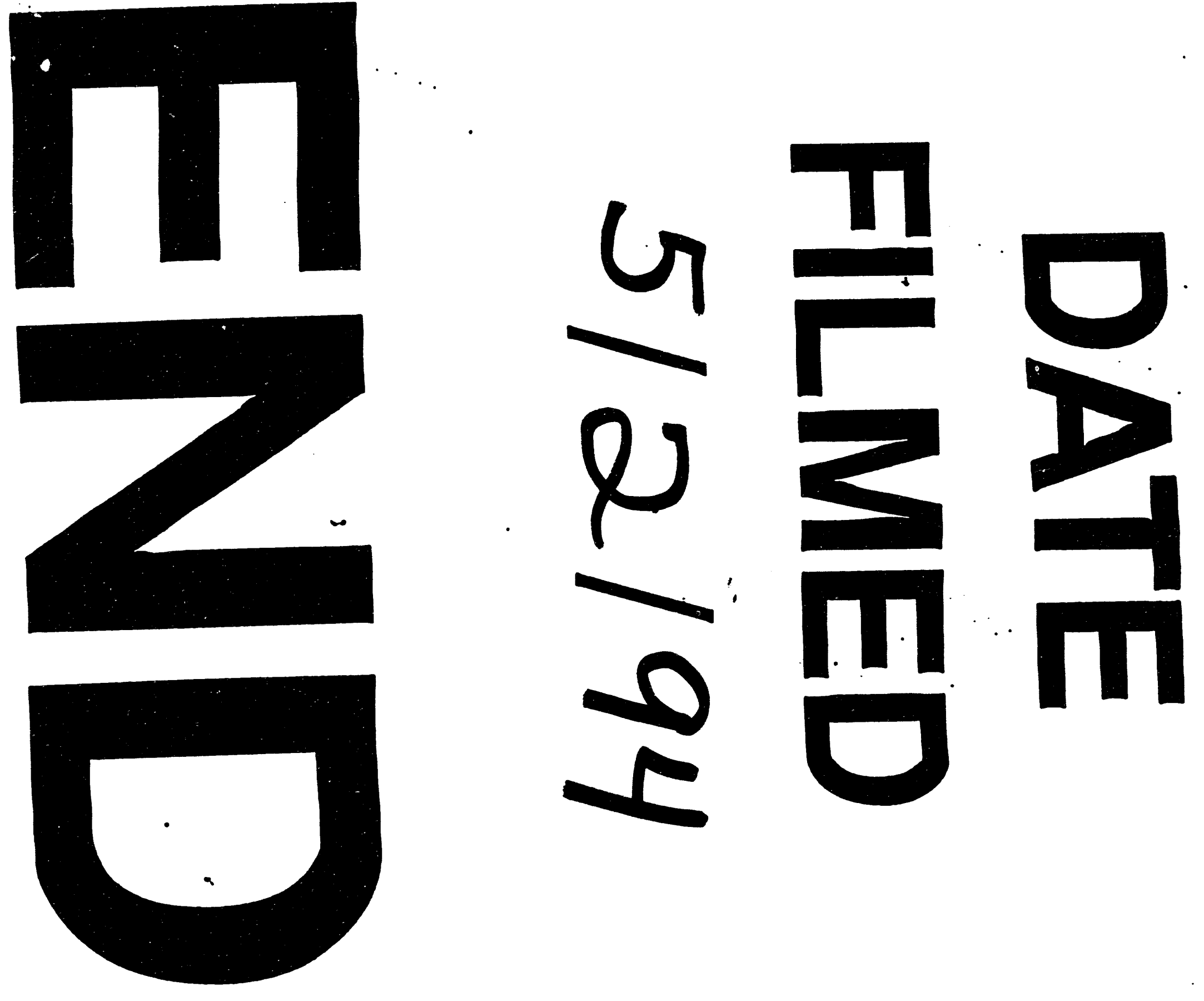


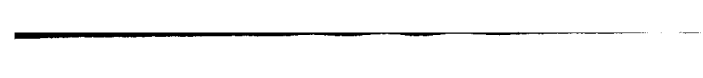

